Terr. Atmos. Ocean. Sci., Vol. 17, No. 4, 871-881, December 2006

\title{
The Characteristics of Fluid Potential in Mud Diapirs Associated with Gas Hydrates in the Okinawa Trough
}

\author{
Ning $\mathrm{Xu}^{1,2}$, Shiguo $\mathrm{Wu}^{1,3, *}$, Xiujuan Wang ${ }^{1,2}$, and Dongdong Dong ${ }^{1,2}$
}

(Manuscript received 16 October 2005, in final form 12 September 2006)

\begin{abstract}
Many mud diapirs have been identified in the southern Okinawa Trough from a seismic survey using R/V KEXUE $I$ in 2001. The movement and accumulation of free gas related to mud diapirs are discussed in detail by an analysis of fluid potential which is based upon velocity data. It can be found that free gas moves from the higher fluid potential strata to the lower ones and the gas hydrate comes into being during free gas movement meeting the proper criteria of temperature and pressure. In fact, gas hydrates have been found in the upper layers above the mud diapirs and in host rocks exhibiting other geophysical characteristics. As the result of the formation of the gas hydrate, the free gas bearing strata are enclosed by the gas hydrate bearing strata. Due to the high pressure anomalies of the free gas bearing strata the fluid potential increases noticeably. It can then be concluded that the high fluid potential anomaly on the low fluid potential background may be caused by the presence of the free gas below the gas hydrate bearing strata.
\end{abstract}

(Key words: Fluid potential, Velocity analysis, Gas hydrate, Mud diapir, Okinawa trough)

\section{INTRODUCTION}

The Okinawa trough is located in the convergent margin between the Eurasia and Pacific plates along the eastern edge of the East China Sea. It is an incipient back-arc basin although

\footnotetext{
${ }^{1}$ Key Laboratory of Marine Geology and Environment, Institute of Oceanology, Chinese Academy of Sciences, Qingdao, China

${ }^{2}$ Graduate School, Chinese Academy of Sciences, Beijing, China

${ }^{3}$ China University of Petroleum, Dongying, China

* Corresponding author address: Dr. Shi-Guo Wu, Institute of Oceanology, Chinese Academy of Sciences, Qingdao, China; E-mail: swu@ms.qdio.ac.cn
} 
there are some questions concerning the rifting stage evolution of the trough and possible distribution of oceanic crust (Jin and Yu 1987; Lee et al. 1980; Letozey and Kimura 1986; Sibuet et al. 1998). The southern Okinawa trough is characterized with the high heat flow which may be beneficial for the formation of hydrocarbon (Luan et al. 2003), and with a well developed active fault system which may provide the necessary channels for the movement of free gas. In addition, Quaternary sediments in the trough are rich in organic materials and have a high sedimentation rate which may be good for the preservation of the organic materials (Qin et al. 1987; Guo et al. 2006). Therefore, the Okinawa Trough provides a good geological environment for the formation of gas hydrates (Guo et al. 2006). Gas hydrate formation in the submarine mud volcanoes or diapirs has retained the attention of many scientists for years (Ginsburg et al. 1994; Milkov 2000; Chen et al. 2006; Chiu et al. 2006; Yang et al. 2006). Mud diapirs have been widely found at the southern Okinawa Trough where the water depths vary from hundreds of meters to more than two thousand meters (Fig. 1). The bottom simulating reflectors with blanking zones above and the reverse polarity character when compared to the seafloor reflection have been found in the upper layers above the mud diapir structure and the host strata indicates the presence of gas hydrates (Guo et al. 2006).

Fluid potential analysis has already been applied widely in the oil exploration industry since its inception (Hubbert 1953). Traditional fluid potential analyses which including oil, gas and water potential analysis, respectively, have been used to study the subsurface hydrodynamics and can help us to understand the processes of oil accumulation and the energy distribution in a sedimentary basin (Zhu 2001; Liu and Shi 2003). Moreover, since the fluid potential analysis has been applied to predict oil accumulation and identify exploration targets, the drilling success rate has improved remarkably. In this paper, we propose a new fluid potential analysis method mainly based on seismic velocity and introduce the fluid potential analysis concept into the prediction and evaluation of the gas hydrate reservoir which may play an important role in assisting the marine gas hydrate prospecting by lowering the degree of necessary exploration.

\section{THE PRINCIPLE OF FLUID POTENTIAL ANALYSIS}

Hubbert (1953) first referenced the concept of fluid potential conception. That potential is defined by the sum of the mechanical energy in the unit fluid weight. In effect, the migration of the fluids, which include oil, gas and water, is controlled by the subsurface fluid potential distribution where the fluids are always migrating from places with a higher fluid potential to places with a lower potential. England (1986) has given an expression for fluid potential, considering the interfacial potential, i.e., capillary potential (England 1986):

$$
\phi=\rho g Z+\rho_{0}^{\int(p)} \frac{d p}{\rho(p)}+\frac{2 \sigma}{r}
$$

Where $\phi$ is the fluid potential, $p$ is the fluid pressure, $\rho(p)$ is the fluid density which is 


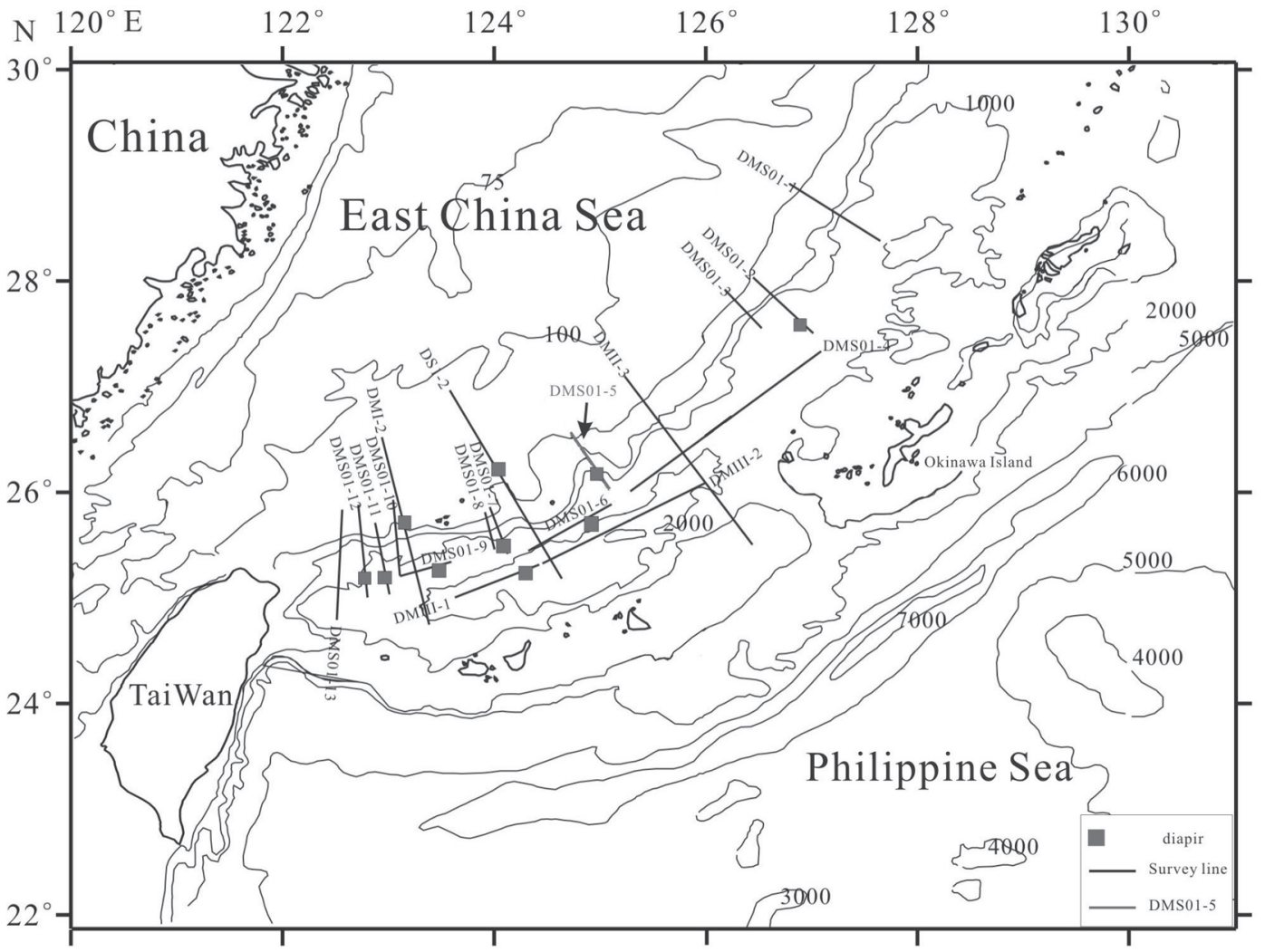

Fig. 1. The position of survey lines in the East China Sea. Isobaths are in meters. Filled red rectangles mark the location of mud diapirs.

pressure dependant, $\sigma$ is the interfacial tension and $\mathrm{r}$ is the radius of the pore throat. Unfortunately, it is difficult to determine the values of $\sigma$ and $r$, so we ignore the capillary potential during the fluid potential calculation and adopt the Hubbert potential model (Hubbert 1953).

The Hubbert potential model in the strata is described as follows:

$$
\phi=\int_{0}^{(p)} \frac{d p}{\rho(p)}+g Z+\frac{1}{2} v^{2},
$$

Where $\phi$ is the fluid potential, $g$ is the acceleration of gravity, $Z$ is the depth below sea level and $v$ is the velocity of the subsurface fluid. Three items express the pressure potential, the positional potential and the kinetic energy, respectively, of the unit fluid mass. In fact, the 
velocity $v$ of the subsurface fluid is so slow $\left(<1 \mathrm{~cm} \mathrm{~s}^{-1}\right)$ that the fluid kinetic energy can be ignored. Moreover, the compressibility of the fluid in the container rock is quite low and the fluid density can be treated as a constant. Consequently, as a result the integration of the pressure potential can be cancelled. A simplified Hubbert potential model can then be described as follows:

$$
\phi_{g}=\frac{P_{f}}{\rho_{g}}+g Z,
$$

Where $\phi_{g}$ is the fluid potential $\left(m^{2} s^{-2}\right), p_{f}$ is the pore fluid pressure $(P a)$ at depth $H, \rho_{g}$ is the gas density $\left(\mathrm{kg} \mathrm{m}^{-3}\right)$ at depth Z. We set the $\rho_{g}$ to be a constant, $150 \mathrm{~kg} \mathrm{~m}^{-3}$, in this paper. $g$ is the acceleration of gravity $\left(\mathrm{m} \mathrm{s}^{-2}\right)$ which is always a constant, and we take it to be $9.8 \mathrm{~m} \mathrm{~s}^{-2}$, and Z is the depth below sea level $(m)$. Therefore, the fluid potential value at a certain subsurface position depends upon the pore fluid pressure in the strata, the depth below sea level, the fluid density and the acceleration of gravity.

The pore fluid pressure $P_{f}$ can be estimated directly by the interval velocities through the Fillippone function (Fillippone 1979):

$$
P_{f}=\left[\left(V_{\max }-V_{i}\right) /\left(V_{\max }-V_{\min }\right)\right] \times D \times G_{p} \times \rho_{s},
$$

Where $P_{f}$ is the pore fluid pressure $(M P a), V_{i}$ is the interval velocity of the ith layer $\left(m s^{-1}\right)$, $V_{\max }$ is the seismic wave velocity of rocks with near zero porosity $\left(m \mathrm{~s}^{-1}\right)$, and the $V_{\min }$ is the seismic wave velocity of rocks with near zero rigidity $\left(\mathrm{m} \mathrm{s}^{-1}\right), D$ is the depth below sea level $(m)$, $G_{p}$ is the formation water pressure gradient which is a constant and we set it to be $9.8 \times 10^{3} \mathrm{kPa}$, $\rho_{s}$ is the formation average density, and the sea water density $\rho_{w}$ is regarded as $1.02 \times 10^{3} \mathrm{~kg} \mathrm{~m}^{-3}$. The ith stratum density is calculated by the Gardner function $\rho_{(i)}=310 \cdot V_{i}^{0.25}$ (Gardner 1974).

We take the stacking velocity as the root mean square velocity $V_{r m s}$ where we ignore the obliquity correction. Then the stacking velocities obtained through the velocity analyses are transformed into the interval velocity $V_{i}$ by the Dix equation (Dix 1955):

$$
V_{i}^{2}=\frac{t_{0, i} V_{r, i}^{2}-t_{0, i-1} V_{r, i-1}^{2}}{t_{0, i}-t_{0, i-1}}
$$

where the $V_{r, i}$ and the $V_{r, i-1}$ are the root mean square velocities $\left(m \mathrm{~s}^{-1}\right)$ of the ith and the i-1th stratum, respectively, the $t_{0, i}$ and the $t_{0, i-1}$ are the two way travel time (s) of the ith and the $\mathrm{i}-1$ th stratum respectively.

In this paper, the $V_{\max }$ and the $V_{\min }$ are calculated as follows (Mohammed et al. 2000):

$$
V_{\max }=1.4 V_{r 0}+3 K t
$$




$$
V_{\text {min }}=0.7 V_{r 0}+0.5 K t \text {, }
$$

where $V_{r 0}$ is the intercept of the root mean velocity $V_{r m s}$ changing along with the two way travel time $t, K$ is the velocity gradient, i.e., $K=\Delta V_{r m s} / \Delta t$.

The pore fluid potential at a certain subsurface position can be calculated by the above analysis and the underground space can then be divided by a series of isopotential lines in which unit mass fluid moves from the high potential line to the adjacent low potential line. It also can be inferred that there is a force field orthogonal to the isopotential lines. It is by the force that the underground pore fluids migrate in the potential decreasing direction. Based on this rule, the distribution of oil, gas and water in the strata can be confirmed, the movement and accumulation of oil can be interpreted in quantity, and the major oil movement path can be definitely predicted. Furthermore, the low fluid potential area can be regarded as the most applicable oil accumulation area.

\section{SEISMIC DATA ACQUISITITION AND PROCESSING}

\subsection{Seismic Data Acquisitition}

The seismic line DMS01-5 analyzed in the paper is chosen from the cruise DH01-07 of R/V KEXUE I, conducted in the East China Sea in July 2001 by the Institute of Oceanology, Chinese Academy of Sciences (Fig. 1). Geophysical characteristics of the seismic profile DMS015 suggest a gas hydrate occurrence (Xu et al. 2006).

The seismic profile DMS01-5 extends from the shelf to the continental slope and further into the inner slope of the Okinawa trough in a NW-SE direction. Furrows developed at the shelf-slope break, which indicates the presence of submarine canyons on the western slope of the trough. There are several faults parallel to the strike direction of the trough on the western slope of the trough. Mud diapir structures are observed at CDP800, CDP2300 and CDP 3000. The mud diapir at CDP800 is especially obvious. The bottom simulating reflectors with blanking zones above have been found in the upper layers above the mud diapir structure and the surrounding strata which indicate the presence of gas hydrates (Fig. 2). The sedimentary strata over the acoustic basement in the southern Okinawa trough can be divided into two stratigraphic sequences (SQ I and II) on the seismic profiles which represent the Quaternary and the Tertiary sequences, respectively. Sequence I extends across the whole trough and can be divided into two subsequences SQ Ia and SQ Ib, indicating Holocene and Pleistocene, respectively (Park et al. 1998; Liu 2001).

\subsection{Velocity Analysis}

In the fluid potential analysis, velocity information is so important that it determines the validity of this method directly. Because the gas hydrate bearing strata are discontinuous in the Okinawa Trough, the velocity is reversed, due to the transition of the seismic waves from the upper gas hydrate bearing sediments into the underlying free gas bearing sediments and may 


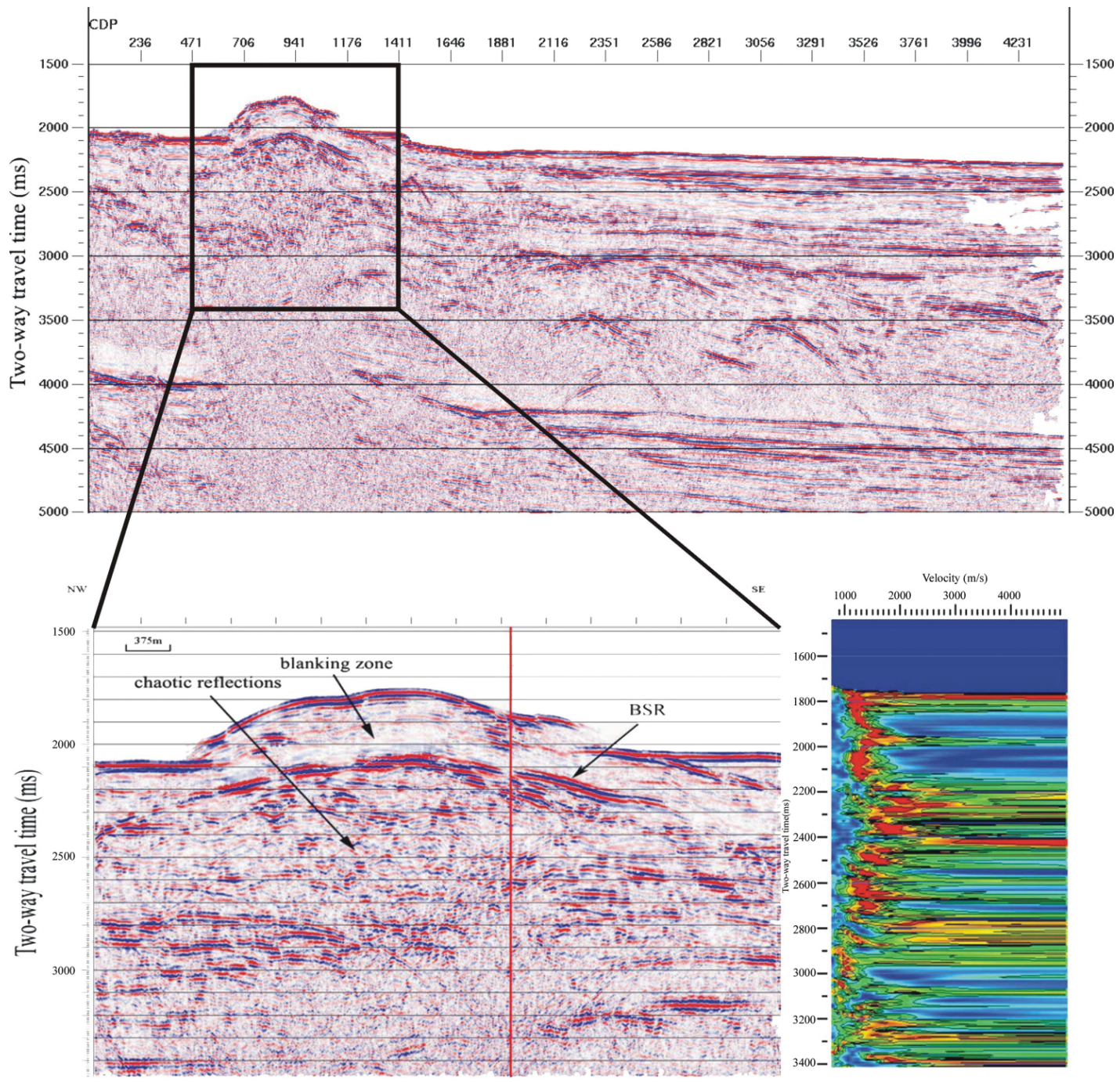

Fig. 2. The stack profile of DMS01-5. The BSR is sub-parallel to the seafloor and is marked by a polarity reversal compared to that of the seafloor. The corresponding velocity spectrum of the red line shown on the right has a high velocity anomaly of about $2000 \mathrm{~m} \mathrm{~s}^{-1}$ at $2300 \mathrm{~ms}$ TWT and a low velocity anomaly below it. These mark the presence of gas hydrate and free gas, respectively. The energy above the seafloor in the velocity spectrum from $1750 \mathrm{~ms}$ to $1900 \mathrm{~ms}$ is caused by the seismic noise above the seafloor which was not muted. The stack section was produced after careful top-mute. 
be neglected in the routine velocity analysis. In addition, velocity errors may damage the normal movement correction, and the effected signal can not be in-phase stacked, resulting in poor resolution (Yilmaz 2001). Consequently, the discontinuous BSR becomes more disperse. Lateral velocity variation is improved by reducing the distance between velocity analysis locations. At the same time, we shorten the grid for the velocity spectrum computation to improve the vertical resolution of the energy group, as a result the trend of the velocity reverse becomes more distinctly. In order to improve $\mathrm{S} / \mathrm{N}$, the supergather is necessary i.e., we take 5 CDP gathers to form one stacking gather at every other 20 CDP gathers for the velocity spectrum analyses. Furthermore, the continuous events in the initial stack profile are chosen as the model events to compute short wavelength residual static correction by the max energy method, and the residual static corrections are applied in new velocity analyses. The velocity spectrum becomes more and more accurate after several iterations as described above. The detailed velocity analysis process is described as follows. First, we take initial velocity analysis after some simple preprocesses; then, we select the strong continuous events on the stacked section for the residual static correction computation, and after prestack noise filtering, amplitude compensation and deconvolution. We then perform the second velocity analysis. Finally, we take the residual static correction and perform the third velocity analysis with shortened grids.

Since gas hydrates found on the western slope of the southern Okinawa Trough usually exist at uplifted structures, which may be because BSRs are crossed with the reflectors of the strata. In the routine velocity analysis, only one of these two crossing events can be chosen to give RMS velocity at the same two-way travel time as the stacking velocity. If we pick the stacking velocities benefit for the horizontal events, the BSR which intersects the horizontal events will be seriously suppressed. So a dip moveout correction is necessary, i.e., to perform a prestack partial migration. The detailed DMO process is described as follows. We perform the normal moveout correction using stacking velocities of the horizontal events to concoct the horizontal normal move-out. Second, we partition the common offset area elements so as to make the CDP numbers uniform in the common offset profile and to avoid the arc phenomenon during the migration. Third, we perform the prestack partial migration in the F-K domain. Finally, we take the reverse normal movement correction using the same horizontal events stacking velocities and then we perform the velocity analysis again. Now, both the horizontal events and the BSRs cross cutting them can be well imagined. As a result, we can derive the exact velocity information related to the BSRs. During the velocity analysis, we not only consider the velocity spectra, the CMP gathers and the multi-velocity scan analyses simultaneous, but also perform the stacking interactively while picking the stacking velocities to enhance the reliability of the velocity. Through these velocity analysis procedures, we are able to obtain the subtle stack velocities for our fluid potential analysis (Fig. 2).

\section{FLUID POTENTIAL ANALYSIS}

The fluids in the strata are controlled mainly by two fluid systems, one is the compaction flow system and the other is the gravity flow system. The fluid potential profile of seismic line DMS01-5 is shown in Fig. 3. It can be found that in the shallow part of the fluid potential 


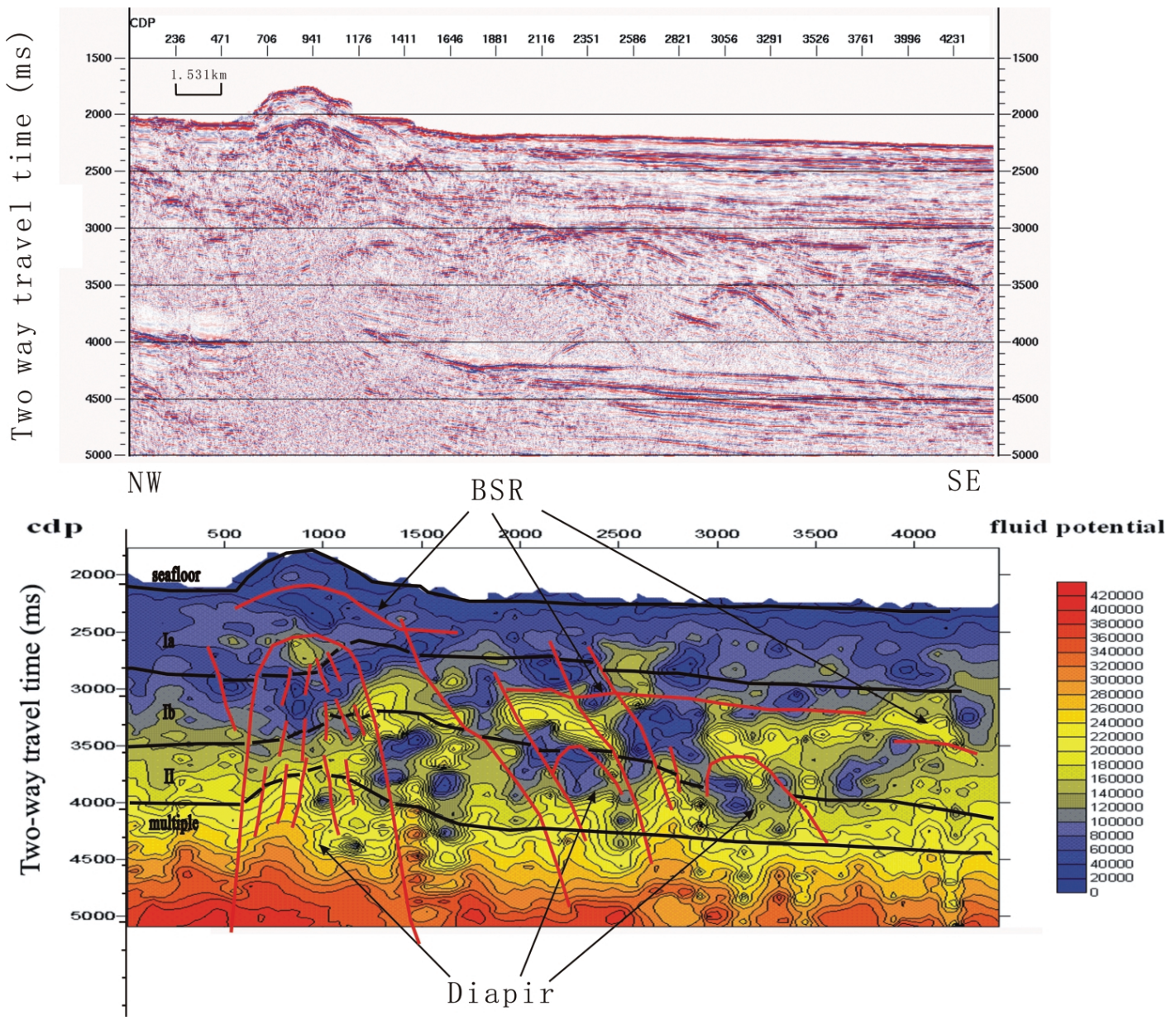

Fig. 3. The stack section (upper) and the fluid potential profile of the survey line DMS01-5 with structural interpretation. The seismic events are mostly continuous and many faults are identified inside and around the diapirs. Distinct BSRs are identified in the layers above the mud diapirs and in the surrounding strata. Ia, Ib, and II are the Holocene, Pleistocene and Pliocene sections, respectively.

profile, the fluid isopotential lines are in general parallel to the strata with slight fluctuations, which indicates that in the shallow strata, the pore fluids are mainly controlled by the gravity flow system, and the free gas mainly migrates vertically. In the medium depth range ( 2.5 to $4 \mathrm{~s})$ of the fluid potential profile, however, the fluid isopotential lines greatly change laterally due to the emergence of the mud diapirs. There are some closed high and low fluid potential con- 
tours which imply that the pore fluids in the medium depth strata are mainly controlled by the compaction flow system, and the free gas migrates laterally. In the deep strata ( $>4 \mathrm{~s}$ ), it can be found that there are large amplitude horizontal fluctuations and relative high potential anomalies are adjacent to relative low potential anomalies, which indicate the pore fluids in the deep strata are controlled both by the compaction flow system and by the gravity flow system at the same time, and the free gas migrates both vertically and laterally.

The high fluid potential anomalies in the low fluid potential background are signs of the presence of free gas below gas hydrates. In the study area, the Miocene or older strata are the source of free gas. Based on the fluid potential analysis, the mud diapir is a low fluid potential area through which free gas moves upwards. There are also low fluid potential areas around the faults which provide channels for the migration of free gas. In the strata surrounding the mud diapirs, the closed high fluid potential anomalies are adjacent to the closed low fluid potential anomalies, thus it can be concluded that free gas migrates from the center of the mud diapir to the surrounding strata along the faults. Since the rock pressure is defined as the pressure of the pore fluids, such as water, oil and gas, the rock pressure is porosity dependant. The decrease of the seismic wave velocity caused by the increase of the porosity results in the increase of the strata pressure, which is the physical mechanism for the prediction of the strata pressure from seismic velocity information. In the Pliocene and Pleistocene strata, there are obvious laterally discontinuous high fluid potential anomalies in the low fluid potential background. It can be imaged that as gas hydrate forms in the strata, the porosity decreases and free gases are trapped by the gas hydrate bearing strata. Due to the presence of free gas, the seismic velocity decreases and the rock pressure increases. Based on the Hubbert potential model, we observed increases on fluid potential.

\section{CONCLUSION}

1. The gases in the strata migrate from high fluid potential areas to low fluid potential areas, and gas hydrates form under the proper temperature and pressure conditions on the way of free gas migration, that in turn prevents the free gas from moving. Since the free gas bearing strata are enclosed by the gas hydrate bearing strata, the high fluid potential anomalies in the low fluid potential background are signs of the presence of free gas below gas hydrates.

2. Mud diapirs develop widely on the northern slope of the southern Okinawa trough and there are many faults in and around the mud diapirs. The Miocene or older strata are the source regions for the free gas. Mud diapirs and faults are always the low fluid potential zones which provide the migration channels for the free gas.

Acknowledgements We would like to thank the Captain and crew of R/V KEXUE I for their support in the field survey. This work is supported by the Knowledge Innovation Key Orientation Project of the Chinese Academy of Sciences (Grant No. KZCX3-SW-224). Our manuscript benefited greatly from the careful and constructive reviews by Hai-Long Lu, CharShine Liu, Tsanyao Frank Yang, Ling Tseng and an anonymous reviewer which helped improve this work considerably. 


\section{REFERENCES}

Chen, D. F., Z. Su, and L. M. Cathles, 2006: Types of gas hydrates in marine environments and their thermodynamic characteristics. Terr. Atmos. Ocean. Sci., 17, 723-737.

Chiu, J. K., W. H. Tseng, and C. S. Liu, 2006: Distribution of gassy sediments and mud volcanoes offshore southwestern Taiwan. Terr. Atmos. Ocean. Sci., 17, 703-722.

Dix, C. H., 1955: Seismic velocities from surface measurement. Geophysics, 20, 68-86.

England, W. A., A. S. Mackenzie, and D. M. Mann, 1986: The movement and entrapment of petroleum fluids in the surface. J. Geol. Soc., 144, 327-347.

Fillippone, W. R., 1979: On the prediction of abnormally pressured sedimentary rocks from seismic data. Offshore Technology Conference, 3662, 2667-2676.

Gardner, G. H. F., 1974: Formation velocity and Density - the Diagnostic Basics for stratigraphic traps. Geophysics, 39, 882-894.

Ginsburg, G. D., and V. A. Soloviev, 1994: Mud volcano gas hydrates in the Caspian Sea. Bull. Geol. Soc. Den., 41, 95-100.

Guo, J. H., S. G. Wu, F. X. Fan, and N. Xu, 2006: The structural features associated with the gas hydrates on the west slop of the Okinawa trough. Oceanol. Limnol. Sin., 35. (in press)

Hubbert, M. K., 1953: Entrapment of petroleum under hydrodynamic condition. AAPG Bull., 37, 1954-2026.

Jin, X. L., and P. Z. Yu, 1987: Structural characteristics of Okinawa Trough. Sci. China Ser. B, 17, 196-203.

Lee, C. S., G. G. Shor, L. D. Bibee, R. S. Lu, and T. W. C. Hilde, 1980: Okinawa Trough : origin of a back-arc basin. Mar. Geol., 35, 219-241.

Letouzey, J., and M. Kimura, 1986: The Okinawa Trough: genesis of a back-arc basin developing along a continental margin. Tectonophysics, 125, 209-230.

Liu, G., and J. Shi, 2003: The Analysis of fluid potential by FPAS: Exemplified by Qiongdongnan Basin. J. East China Geol. Inst., 26, 337-342. (in Chinese)

Liu, J. H., 2001: Features of seismic reflection wave in South Okinawa Trough and geological interpretation. Donghai Mar. Sci., 19, 19-26. (in Chinese)

Luan, X. W., Y. S. Qin, and X. H. Zhang, 2003: The stability zone of gas hydrate in the slope of East China Sea and neighboring trough basin area. Chin. J. Geophys., 46, 467-475. (in Chinese)

Milkov, A. V., 2000: Worldwide distribution of submarine mud volcanoes and associated gas hydrates. Mar. Geol., 167, 29-42.

Mohammed, A. B., M. S. Colin, and A. Rashad, 2000: A feasibility study for pore-pressure prediction using seismic velocities in the offshore Nile Delta, Egypt. The Leading Edge, 19, 1103-1107.

Park, J. O., H. Tokuyama, M. Shinohara, K. Suyehiro, and A. Taira, 1998: Seismic record of tectonic evolution and backarc rifting in the southern Ryukyu island arc system. Tectonophysics, 294, 21-37.

Qin, Y. S., Y. Y. Zhao, and L. R. Chen, 1987: Geology of the East China Sea. Beijing Science Press, 200 pp. 
Sibuet, J. C., B. Deffontaines, and S. K. Hsu, 1998: Okinawa Trough back-arc basin: early tectonic and magmatic evolution. J. Geophys. Res., 103, 30245-30267.

Xu, N., S. G. Wu, X. J. Wang, and J. H. Guo, 2006: Seismic study of the gas hydrate in the continental slope of the okinawa trough, east china sea. Prog. Geophys., 2, 564-571. (in Chinese)

Yang, T. F., P. C. Chuang, S. Lin, J. C. Chen, Y. Wang, and S. H. Chung, 2006: Methane venting in gas hydrate potential area offshore of SW Taiwan: evidence of gas analysis of water column samples. Terr. Atmos. Ocean. Sci., 17, 933-950.

Yilmaz, O., 2001: The seismic data processing-Processing, inversion and interpretation of seismic data, Tulsa Society of Exploration Geophysicists, 2024 pp.

Zhu, H. T., 2001: Fluid potential analysis study and application. J. Xinjiang Petrol. Inst., 13, 9-14. (in Chinese)

Xu, N., S. Wu, X. Wang, and D. Dong, 2006: The characteristics of fluid potential in mud diapirs associated with gas hydrates in the Okinawa Trough. Terr. Atmos. Ocean. Sci., 17, 871-881. 